\title{
Data automated bag breathing unit for COVID-19 ventilator shortages
}

\author{
Aleksandra B. Gruslova ${ }^{1 *} \mathbb{B}$, Nitesh Katta ${ }^{2,3}$, Andrew G. Cabe' ${ }^{1}$ Scott F. Jenney ${ }^{3}$, Jonathan W. Valvano ${ }^{3}$, \\ Tim B. Phillips ${ }^{3}$, Austin B. McElroy ${ }^{3}$, Robert K. LaSalle ${ }^{4}$, Aydin Zahedivash ${ }^{3}$, Van N. Truskett ${ }^{3}$, Nishi Viswanathan ${ }^{6}$, \\ Marc D. Feldman ${ }^{1}$, Richard B. Wettstein ${ }^{5}$,Thomas E. Milner ${ }^{2,3}$ and Stephen Derdak ${ }^{5}$
}

${ }^{*}$ Correspondence: gruslova@uthscsa.edu

1 Department of Medicine, UT Health San Antonio, 7703 Floyd Curl Drive, DTL 5.532U, San Antonio, TX 78229, USA Full list of author information is available at the end of the article

\begin{abstract}
Background: The COVID-19 pandemic has caused a global mechanical ventilator shortage for treatment of severe acute respiratory failure. Development of novel breathing devices has been proposed as a low cost, rapid solution when full-featured ventilators are unavailable. Here we report the design, bench testing and preclinical results for an 'Automated Bag Breathing Unit'(ABBU). Output parameters were validated with mechanical test lungs followed by animal model testing.
\end{abstract}

Results: The ABBU design uses a programmable motor-driven wheel assembled for adult resuscitation bag-valve compression. ABBU can control tidal volume (200-800 ml), respiratory rate (10-40 bpm), inspiratory time (0.5-1.5 s), assist pressure sensing $\left(-1\right.$ to $\left.-20 \mathrm{~cm} \mathrm{H}_{2} \mathrm{O}\right)$, manual PEEP valve $\left(0-20 \mathrm{~cm} \mathrm{H}_{2} \mathrm{O}\right)$. All set values are displayed on an LCD screen. Bench testing with lung simulators (Michigan 1600, SmartLung 2000) yielded consistent tidal volume delivery at compliances of 20, 40 and 70 ( $\mathrm{mL} / \mathrm{cm} \mathrm{H}_{2} \mathrm{O}$ ). The delivered fraction of inspired oxygen $\left(\mathrm{FiO}_{2}\right)$ decreased with increasing minute ventilation $\left(V_{E}\right)$, from 98 to $47 \%$ when $V_{E}$ was increased from 4 to $16 \mathrm{~L} / \mathrm{min}$ using a fixed oxygen flow source of $5 \mathrm{~L} / \mathrm{min}$.

ABBU was tested in Berkshire pigs ( $n=6$, weight of $50.8 \pm 2.6 \mathrm{~kg}$ ) utilizing normal lung model and saline lavage induced lung injury. Arterial blood gases were measured following changes in tidal volume $(200-800 \mathrm{ml})$, respiratory rate $(10-40 \mathrm{bpm})$, and PEEP $\left(5-20 \mathrm{~cm} \mathrm{H}_{2} \mathrm{O}\right)$ at baseline and after lung lavage. Physiological levels of $\mathrm{PaCO}_{2}$ ( $\leq 40 \mathrm{~mm} \mathrm{Hg}[5.3 \mathrm{kPa}]$ ) were achieved in all animals at baseline and following lavage injury. $\mathrm{PaO}_{2}$ increased in lavage injured lungs in response to incremental PEEP $(5-20 \mathrm{~cm}$ $\left.\mathrm{H}_{2} \mathrm{O}\right)(p<0.01)$. At fixed low oxygen flow rates $(5 \mathrm{~L} / \mathrm{min})$, delivered $\mathrm{FiO}_{2}$ decreased with increased $V_{\mathrm{E}}$.

Conclusions: $A B B U$ provides oxygenation and ventilation across a range of parameter settings that may potentially provide a low-cost solution to ventilator shortages. A clinical trial is necessary to establish safety and efficacy in adult patients with diverse etiologies of respiratory failure.

Keywords: ABBU, Emergency resuscitator, Bag valve resuscitator, Lung injury, Acute respiratory distress syndrome, COVID-19, Ventilator shortage author(s) and the source, provide a link to the Creative Commons licence, and indicate if changes were made. The images or other third party material in this article are included in the article's Creative Commons licence, unless indicated otherwise in a credit line to the material. If material is not included in the article's Creative Commons licence and your intended use is not permitted by statutory regulation or exceeds the permitted use, you will need to obtain permission directly from the copyright holder. To view a copy of this licence, visit http:// creativecommons.org/licenses/by/4.0/. 


\section{Background}

On January 31, 2020, the US Department of Health \& Human Services announced a public health emergency related to a novel coronavirus, SARS-CoV-2, and the disease it causes, COVID-19 [1]. The early rapid spread of the COVID-19 pandemic resulted in a shortage of mechanical ventilators and accessory components (e.g., humidifiers, circuits, etc.) in many regions throughout the world [2-5]. In response to these shortages, a global surge in development and production occurred, including repurposing non-medical device assembly lines to manufacture quickly designed ventilators (e.g., FORD, GM, Virgin, etc.) [6-9].

As of March 2021, over 150 million COVID-19 cases have been identified leading to over 3.0 million deaths worldwide [10]. Among hospitalized patients, $30 \%$ require care at intensive care unit (ICU) and $29 \%$ or more of those require mechanical ventilation [11].

In response to the shortage of mechanical ventilators to treat COVID-19 patients, resuscitation bag-valve breathing devices were conceived as a potential solution for short-term emergency use. The FDA has classified these devices as "emergency resuscitators" to distinguish them from mechanical ventilators [12-16]. Our design uses a self-inflating resuscitation bag-valve, an automobile windshield motor, and lever arm to mimic manual hand bag-valve ventilation-along with essential operator controllable parameters: tidal volume $\left(V_{T}\right)$, respiratory rate $(\mathrm{RR})$, inspiratory time $\left(T_{I}\right)$, positive end-expiratory pressure (PEEP) and patient-initiated breath pressure sensing. ABBU uses readily available components, low flow $\mathrm{O}_{2}$ sources, standard electrical power, and can be rapidly mass produced at lower cost $(\$ 2,000$ estimated at $2021, \sim 5 \mathrm{~h}$ per unit production) compare to the full featured ICU ventilator $(\$ 25,000-\$ 50,000)$.

The purpose of this study was to determine if $A B B U$ can provide oxygenation and ventilation in a mechanical test lung and preclinical porcine model across a range of clinically relevant parameter settings.

\section{Methods}

\section{Design: mechanical, electrical, software, safety}

ABBU was designed to replace manual ventilation of a bag valve resuscitator when a conventional ventilator device is unavailable (Fig. 1A, B). ABBU features include $V_{T}$ (200-800 mL), RR (10-40 bpm), $T_{I}(0.5-1.5 \mathrm{~s})$, and adjustable patient-initiated breath sensing ( -1 to $-20 \mathrm{~cm} \mathrm{H}_{2} \mathrm{O}$ ). ABBU can use low flow oxygen (5-15 L/min) from widely available sources (e.g., concentrators, hospital wall-source, tanks, and liquid oxygen reservoirs).

$A B B U$ senses the patient inspiratory effort below a software-calculated pressure threshold to trigger a breath. Patient-ABBU synchrony is facilitated by clinician titration of the triggering threshold. Auto-cycling can be reduced by increasing the triggering threshold (e.g., more negative). Conversely, ineffective triggering is reduced by decreasing the sensing threshold (e.g., less negative). Patients unable to trigger breaths (e.g., weakness, neuromuscular blocker-induced paralysis, central apneas) receive mandatory breaths at the set $V_{T}$, RR, and $T_{I}$. Total $\mathrm{RR}$ will be determined by the patient-triggered rate and the set rate. 

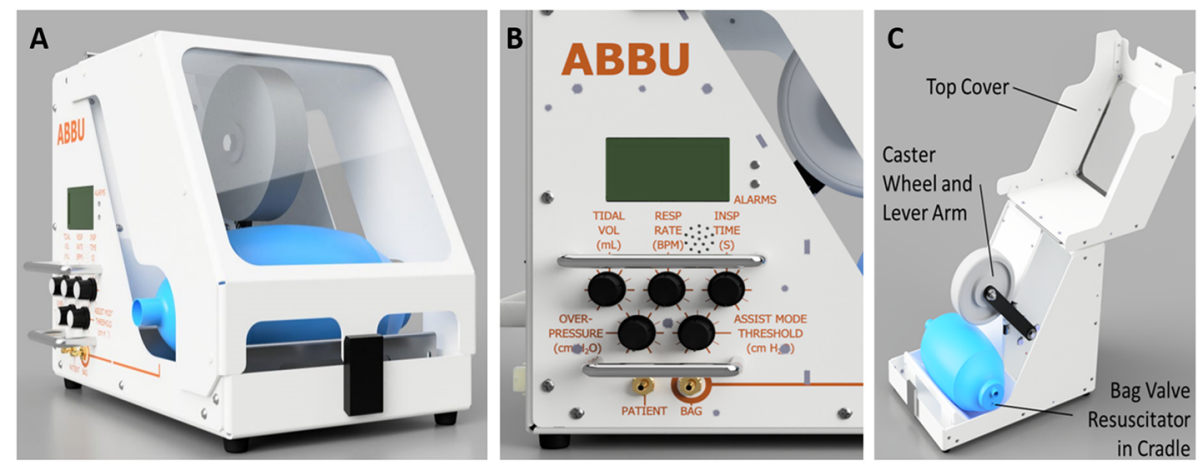

\section{D}

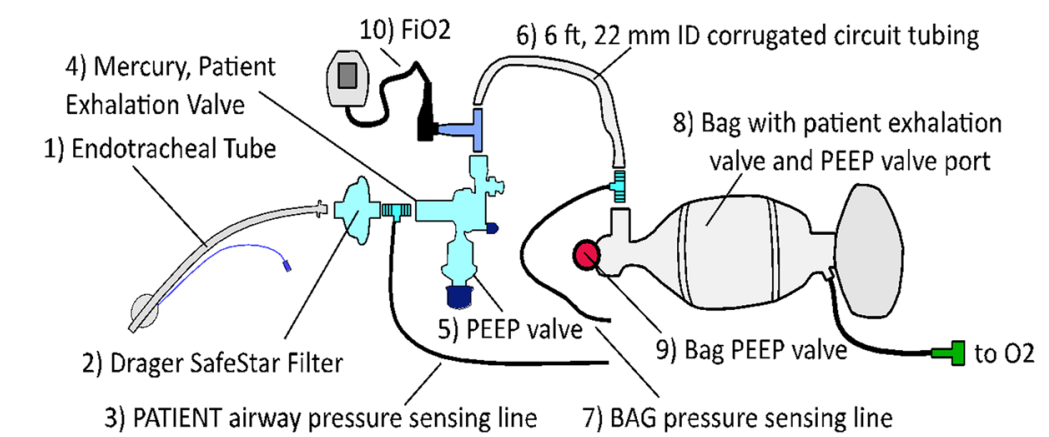

Fig. 1 Automated Bag Breathing Unit (ABBU) and breathing circuit. A ABBU. B Front panel with LCD display and adjustment knobs. C ABBU cover openings. D ABBU breathing circuit used for testing. Porcine experiments added a sidestream $\mathrm{ETCO}_{2}$ analyzer between components 2 and 3)

ABBU provides visual and auditory alarms for circuit blockage, air-leaks, low pressure (e.g., disconnection), high airway pressure (50-70 $\left.\mathrm{cm} \mathrm{H}_{2} \mathrm{O}\right)$, motor, and electric failure. The audible power loss alarm has a backup battery. A high visibility enclosure facilitates rapid troubleshooting of the circuit and motor-bag interface (Fig. 1B). If ABBU fails, clinicians can quickly open the enclosure to access the bag and provide manual ventilation (Fig. $1 \mathrm{C}$ ). This capability is a key safety feature of the ABBU design.

Figure 1D shows the breathing circuit components used in animal experiments. The patient exhalation valve (CPR-2 bag, Mercury Medical, Clearwater, FL) includes a manual adjustable PEEP valve. The resuscitator bag (adult $\mathrm{Ambu}^{\circledR} \mathrm{Spur}^{\circledR}$ II bag, AMBU Inc., Columbia, MD) is centered in a cradle and secured on both ends by an elastic cord inside the unit. The bag PEEP valve (Ambu Disposable PEEP Valve, $0-20 \mathrm{~cm} \mathrm{H}_{2} \mathrm{O}$ size) is set to $0 \mathrm{~cm} \mathrm{H}_{2} \mathrm{O}$, and PEEP is adjusted manually on a second PEEP valve interfaced to the patient exhalation valve. Two pressure sensing lines (3/16" ID, $22 \mathrm{~mm}$ OD AirLife connector) are used for circuit pressure monitoring and breath triggering assist. An $\mathrm{FiO}_{2}$ analyzer $\left(\mathrm{MaxO}^{2}+\mathrm{AE}\right.$, Maxtec, Salt Lake City, UT) was interfaced into the breathing circuit for all animal experiments. 


\section{Bench testing}

A Michigan adult dual-lung simulator (Model 1600, Michigan Instruments, USA) and Ventilator Validation System (VVK100-SYS, BIOPAC Systems, Goleta, CA) was used to validate ventilator parameters. ABBU was tested at compliances of 20,40 and $70 \mathrm{~mL} / \mathrm{cm}$ $\mathrm{H}_{2} \mathrm{O}$ with resistances $5-50 \mathrm{~cm} \mathrm{H}_{2} \mathrm{O} /(\mathrm{L} / \mathrm{s}) . \mathrm{V}_{\mathrm{T}}$ of $200,400,600$ and $800 \mathrm{~mL}$ were tested across a range of compliances and resistance levels. For performance experiments, RR was set at $15 \mathrm{bpm}$ and the PEEP was set at $15 \mathrm{~cm} \mathrm{H}_{2} \mathrm{O}$. Twenty breath cycles were collected for each measurement and processed to validate measures of $V_{T}$, pressure, $T_{I}, R R$, and confirm PEEP value.

Durability and $\mathrm{V}_{\mathrm{T}}$ stability of different brand resuscitation bags: AMBU (SPUR II, Ambu, Columbia, MD), HUDSON (RCI 5387, Teleflex, Morrisville, NC), MEDLINE (CPRM1116, Medline, Northfield, IL), Mercury (CPR-2, Mercury Medical, Clearwater, Florida) were evaluated on mechanical test lungs (SmartLung 2000, IMT Analytics, Buchs, Switzerland) at maximum RR (50 bpm) and $T_{I}$ of $0.5 \mathrm{~s}$ continuously over 7 days. Cardone electric motors (Model 85-3024, Cardone Industries, Ontario, CA) were operated continuously for $>30$ days to assess durability.

\section{Animal testing}

Animal procedures were approved by the Institutional Animal Care and Use Committee at the University of Texas Health Science Center at San Antonio. Studies were performed on 6 healthy female pigs (Berkshire, $50.8 \pm 2.6 \mathrm{~kg}$ ). Pigs were sedated via tiletamine-zolazepam (Telazol,4-8 mg/kg IM), Zylazine (1-2.2 mg/kg IM), and 3-4\% Isoflurane, followed by endotracheal intubation and maintenance on $0.5-3 \%$ Isoflurane. Body temperature was kept in the normal range $\left(38-39^{\circ} \mathrm{C}\right)$ by heated pad. Arterial pulse pressure was monitored by a micromanometer pressure sensor in the descending thoracic aorta. After collection of baseline blood samples, ABBU was connected to the proximal end of the endotracheal tube by a 90-degree adapter plugged into the breathing circuit, which included the $\mathrm{FiO}_{2}$ analyzer and side-stream $\mathrm{ETCO}_{2}$ analyzer (Fig. 1D).

ABBU settings were changed in accordance with the experimental protocol. $T_{I}$ was kept constant $(1 \mathrm{~s})$ during the entire experiment. Baseline testing was performed on healthy lungs, followed by testing on saline injured lungs. Neuromuscular paralysis was used as needed (vecuronium, IV, 0.1-0.2 mg/kg). Heart rate (HR), blood pressure (BP) and body temperature (rectal) were monitored continuously. Pigs were euthanized using Euthasol solution (pentobarbital sodium and phenytoin sodium, IV, $100 \mathrm{mg} / \mathrm{kg}$ ) following completion of experiments $(6-8 \mathrm{~h})$.

Saline lung lavage was performed as previously described [17]. In brief, warmed saline $(30 \mathrm{~mL} / \mathrm{kg}$ ) was poured into the lungs through a funnel. As arterial pressure fell below $50 \mathrm{~mm} \mathrm{Hg}$, lavage fluid was drained passively. The animal was reconnected to ABBU with an $\mathrm{O}_{2}$ flow rate of $15 \mathrm{~L} / \mathrm{m}$ and $\mathrm{RR}$ was adjusted to maintain arterial $\mathrm{pH}>7.25$. Lavages were repeated until partial pressure of oxygen $\left(\mathrm{PaO}_{2}\right)$ was $<100 \mathrm{~mm} \mathrm{Hg}[13.3 \mathrm{kPa}]$ for $30 \mathrm{~min}$.

Arterial blood samples were analyzed by CG4 + cartridges (iSTAT analyzer, Abbott, IL, USA). Blood gas responses for different $V_{\mathrm{T}}$, RR and PEEP were compared with their respective baselines for normal and lung injury model. Parameters: $\mathrm{FiO}_{2}(\%), \mathrm{HR}(\mathrm{bpm})$, 
$\mathrm{RR}(\mathrm{bpm}), \mathrm{ETCO}_{2}(\mathrm{~mm} \mathrm{Hg}), \mathrm{SpO}_{2}(\%)$, and $\mathrm{BP}(\mathrm{mm} \mathrm{Hg})$, were recorded concurrent with blood sample collection.

\section{Statistical analysis}

Data in graphs is shown as mean $\pm \mathrm{SE}$. Two-tail $T$ test and one-way ANOVA were used for all comparisons. A value of $p<0.05$ was considered statistically significant. Pearson Correlation Coefficient (PCC) was computed to test correlation between two variables.

\section{Results}

\section{Bench testing}

\section{Durability testing of bags and motors}

Three Cardone motors were continuously operated at constant $V_{T}(800 \mathrm{~mL})$ and $\mathrm{RR}$ (50 bpm) for 32 days. The motor temperature was monitored. The testing was discontinued after Motor 1 overheated (up to $73{ }^{\circ} \mathrm{C}$ ) and stopped operating (Fig. 2A). Only one of the 5 tested motors reached this temperature.

In addition, the performance of four brands of bags (AMBU Spur II, Hudson, Medline, Mercury) was tested with $A B B U$ running continuously for 7 days at $V_{T} 800 \mathrm{ml}$ and RR $50 \mathrm{bpm}$. Data for each bag was collected at $\mathrm{V}_{\mathrm{T}}$ of $400 \mathrm{~mL}$. The correlation slope and standard deviation were calculated to indicate when bag performance started to decline. A slope correlation closest to 1 indicates bag is able to achieve the targeted $V_{T}$ for all parameters in the test matrix. The AMBU Spur II bag performed the best (correlation slope between 0.93 and 1.03, data not provided). Figure 2B shows experiments with seven Spur II AMBU bags. Values computed from the Ventilator Validation System (BIOPAC System, Inc.) data were consistent with the set controls on the ABBU instrument. The data demonstrates the consistent performance of AMBU Spur II bag ( $400 \mathrm{~mL}$ $V_{T}, 15 \mathrm{bpm} \mathrm{RP}, 1 \mathrm{~s} T_{I}$ ) over 7 days of continuous ABBU operation. At day 4, there was

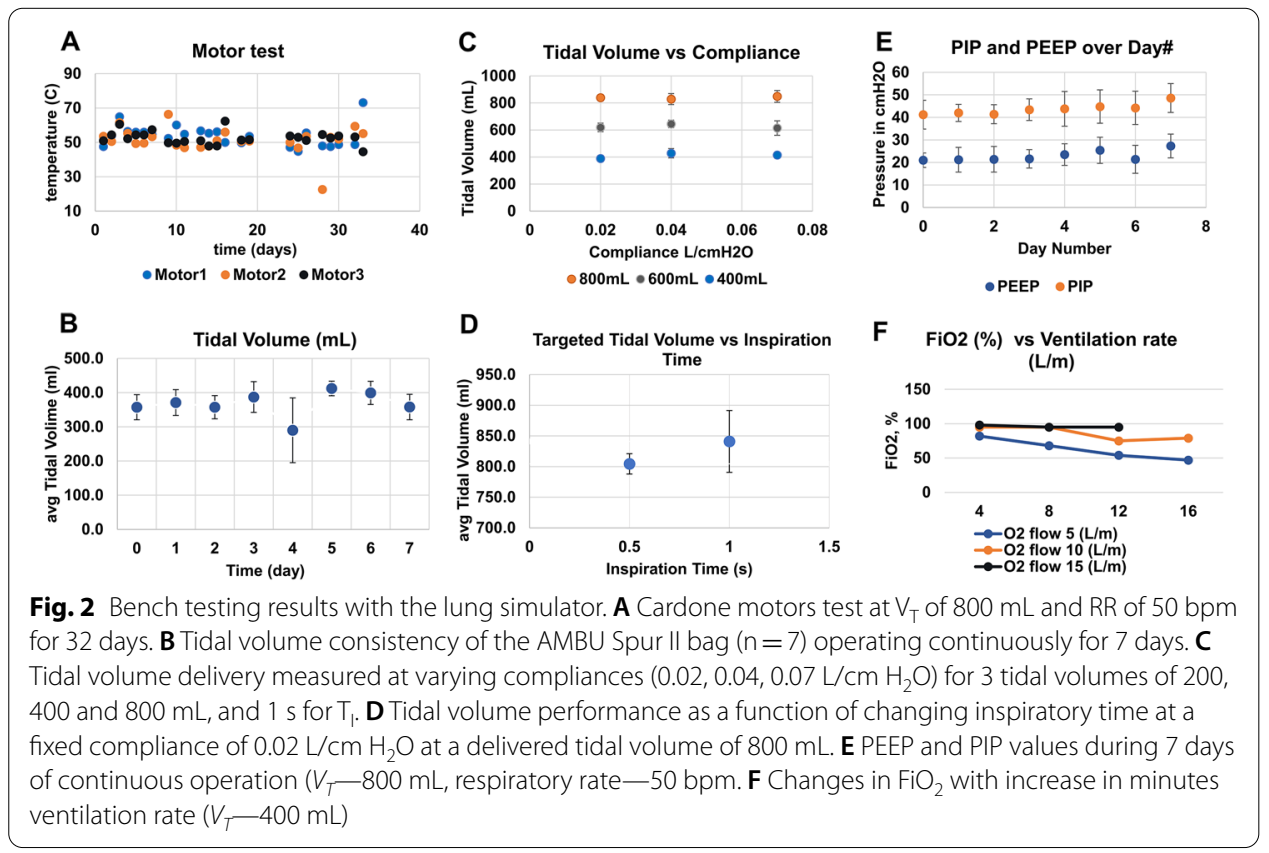


a significant variation in $\mathrm{V}_{\mathrm{T}}$ resulting from a shift of bag position in the cradle. AMBU bag degradation (scratches, loss of elasticity, loss of compliance) was observed after continuous operation (RR $50 \mathrm{bpm}, T_{I}-0.5 \mathrm{~s}, V_{T} 800 \mathrm{~mL}$ ) starting at day 4; however, performance was still adequate. Performance declined after 7 days, after which replacing the bag is recommended.

\section{Accuracy of controls of instruments}

Targeted $\mathrm{V}_{\mathrm{T}}$ of $400 \mathrm{~mL}$ was consistently delivered ( $\mathrm{SD} \leq 50 \mathrm{~mL}$ ) to the Michigan test lung at varying compliances $\left(20,40,70 \mathrm{~mL} / \mathrm{cm} \mathrm{H}_{2} \mathrm{O}\right)$ and $\mathrm{T}_{\mathrm{I}}$ settings $(0.5,1 \mathrm{~s})$ (Fig. $2 \mathrm{C}$, D).

PEEP and PIP showed minimal variation during continuous operation of ABBU for 7 days at $V_{T}$ of $800 \mathrm{~mL}$ and RR of $50 \mathrm{bpm}$ (Fig. 2E).

$\mathrm{FiO}_{2}$ decreased significantly with increasing $\mathrm{RR}$ at a constant $V_{T}(400 \mathrm{~mL})$ and fixed oxygen flow rate of $5 \mathrm{~L} / \mathrm{m}$ (Fig. $2 \mathrm{~F}$ ).

\section{Animal testing}

ABBU was tested in a porcine model at baseline and following saline lavage lung injury. Data was obtained sequentially on the same animal over 6-8 h. HR, BP and body temperature were maintained within physiological levels throughout experimentation.

\section{Normal lung}

Before experiments, the blood gas and hemodynamic responses from switching to ABBU were compared with the veterinary ventilator baseline (Narkomed 2B, Drager, Germany). Switching from the veterinary ventilator $\left(\mathrm{FiO}_{2} 100 \%\right)$ to $\mathrm{ABBU}\left(\mathrm{FiO}_{2} 73 \%\right)$ caused a decrease in $\mathrm{PaO}_{2}$ from $467.5 \pm 25.8 \mathrm{~mm} \mathrm{Hg}[62.3 \pm 3.4 \mathrm{kPa}]$ to $307.3 \pm 51.9 \mathrm{~mm} \mathrm{Hg}$ $\left[41 \pm 6.9 \mathrm{kPa}\right.$ ] attributed to the difference in $\mathrm{FiO}_{2}$ between the two devices (Table 1). The blood gas responses at different $V_{T}$ and RR were compared with their respective baseline values (Fig. 3) at constant $T_{I}(1 \mathrm{~s}), \operatorname{PEEP}\left(5 \mathrm{~cm} \mathrm{H}_{2} \mathrm{O}\right)$, and flow rate $(5 \mathrm{~L} / \mathrm{min})$. Mean $\mathrm{PaCO}_{2}$ in arterial blood at baseline $V_{T}(200 \mathrm{~mL})$ was $74.8 \pm 3.8 \mathrm{~mm} \mathrm{Hg}[10 \pm 0.5 \mathrm{kPa}]$. Figure 3A demonstrates that increasing $V_{T}$ and with fixed RR at $20 \mathrm{bpm}$, lowered $\mathrm{PaCO}_{2}$ to physiological level $(\leq 40 \mathrm{~mm} \mathrm{Hg}[5.3 \mathrm{kPa}])$ in all animals $(p<0.001)$. Changes from high to low $\mathrm{PaCO}_{2}$ (e.g., low to high $V_{E}$ ) was associated with significant decreases in $\mathrm{FiO}_{2}\left(0.998\right.$ PCC) similar to test lung data using a fixed oxygen flow rate. Increases in $V_{E}$ decreased delivered $\mathrm{FiO}_{2}$ at all combinations of $V_{T}$ and $\mathrm{RR}$. The response of $\mathrm{PaCO}_{2}$ to changes in RR, while keeping $V_{T}$ constant is shown in Fig. 3B.

Table 1 Gas exchange and hemodynamics

\begin{tabular}{|c|c|c|c|c|c|c|c|}
\hline Ventilator & $\mathrm{FiO}_{2}, \%$ & $\begin{array}{l}\mathrm{CO}_{2}, \mathrm{~mm} \mathrm{Hg} \\
{[\mathrm{kPa}]}\end{array}$ & $\mathrm{SpO}_{2}, \%$ & $\mathrm{pH}$ & $\begin{array}{l}\mathrm{PaCO}_{2}, \mathrm{~mm} \\
\mathrm{Hg}[\mathrm{kPa}]\end{array}$ & $\begin{array}{l}\mathrm{PaO}_{2}, \mathrm{~mm} \\
\mathrm{Hg}[\mathrm{kPa}]\end{array}$ & $\mathrm{SaO}_{2}, \%$ \\
\hline $\begin{array}{l}\text { Veterinary } \\
\text { ventilator }\end{array}$ & $100 \pm 0$ & $\begin{array}{l}41.5 \pm 0.8 \\
{[5.5 \pm 0.1]}\end{array}$ & $\begin{array}{l}97.8 \pm 0.8 \\
{[13.0 \pm 0.1]}\end{array}$ & $7.5 \pm 0.01$ & $\begin{array}{l}45.5 \pm 1.9 \\
{[6.1 \pm 0.3]}\end{array}$ & $\begin{array}{l}467.5 \pm 25.8 \\
{[62.3 \pm 3.4]}\end{array}$ & $100 \pm 0$ \\
\hline ABBU & $72.7 \pm 10.1^{a}$ & $\begin{array}{l}43.8 \pm 2.6^{b} \\
{[5.8 \pm 0.3]}\end{array}$ & $\begin{array}{l}95.8 \pm 0.9^{b} \\
{[12.8 \pm 0.1]}\end{array}$ & $7.4 \pm 0.1^{b}$ & $\begin{array}{l}51.3 \pm 8.2^{b} \\
{[6.8 \pm 1.1]}\end{array}$ & $\begin{array}{l}307.3 \pm 51.9^{a} \\
{[41.0 \pm 6.9]}\end{array}$ & $100 \pm 0$ \\
\hline
\end{tabular}

Summary of $\mathrm{O}_{2}$ and $\mathrm{CO}_{2}$ exchange with the veterinary ventilator and ABBU. Two-tail $T$ test was used for comparisons. All results are mean $\pm \mathrm{SE}$

${ }^{a} p<0.05$ vs veterinary ventilator; ${ }^{b} p>0.05$ vs veterinary ventilator 

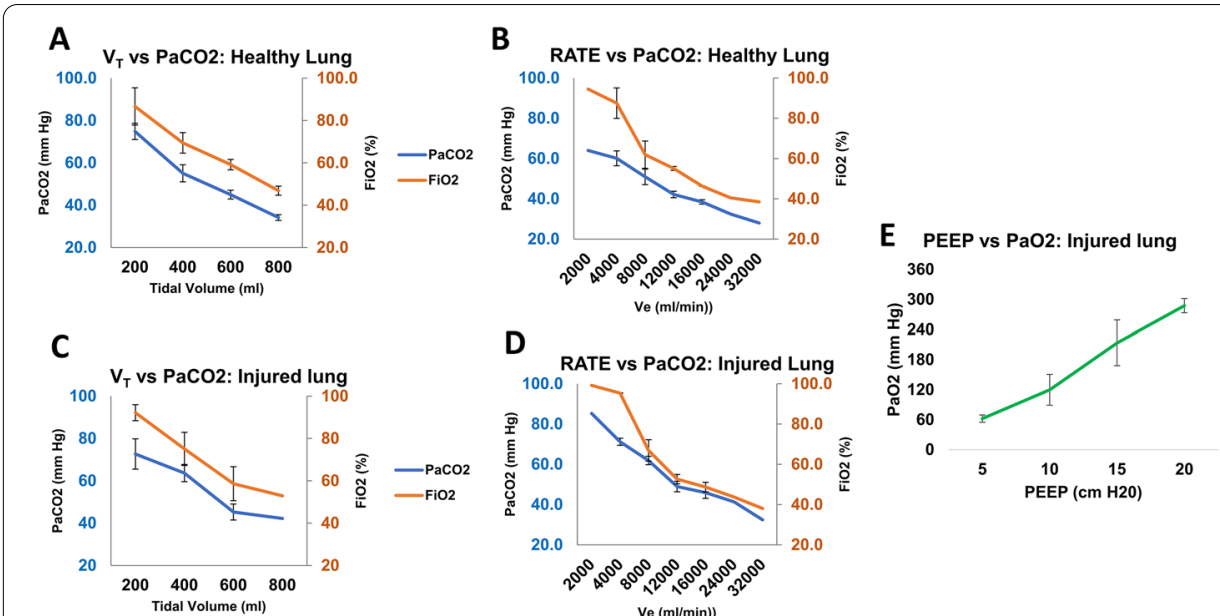

Fig. 3 Porcine study results $(n=6)$. A, B Variation of $\mathrm{PaCO}_{2}$ and $\mathrm{PaO}_{2}$ by adjusting Tidal volume, Respiratory Rate or PEEP in normal or $\mathbf{C}-\mathbf{E}$ injured lung porcine model. $T_{1}(1 \mathrm{~s})$ and oxygen flow rate $(5 \mathrm{~L} / \mathrm{min})$ were kept constant during experiments. All results are mean \pm SE

\section{Saline lavage lung injury}

Hypoxemia following saline lavage was confirmed in all six pigs. The average arterial $\mathrm{PaO}_{2}, \mathrm{PaCO}_{2}$ and $\mathrm{pH}$ at baseline was $69.5 \pm 8.6 \mathrm{~mm} \mathrm{Hg}[9.3 \pm 1.1 \mathrm{kPa}], 43.1 \pm 2.2 \mathrm{~mm} \mathrm{Hg}$ $[57.5 \pm 0.3 \mathrm{kPa}]$ and $7.4 \pm 0.02$, respectively.

Similar to pre-lavage baseline, an increase in $\mathrm{V}_{\mathrm{T}}$ while maintaining a constant $\mathrm{RR}$ $(20 \mathrm{bpm})$ led to a significant decrease in arterial $\mathrm{PaCO}_{2}$ level $(p<0.005)$ and $\mathrm{FiO}_{2}$. Mean $\mathrm{PaCO}_{2}(\mathrm{~mm} \mathrm{Hg}[\mathrm{kPa}])$ at $200 \mathrm{~mL}, 400 \mathrm{~mL}$ and $600 \mathrm{~mL}$ was $72.7 \pm 7.1[9.7 \pm 0.9]$, $63.7 \pm 4.1[8.5 \pm 0.5]$ and $45.3 \pm 3.8$ [6.0 \pm 0.5$]$, respectively. Increasing RR, demonstrated a similar decline in $\mathrm{PaCO}_{2}(p<0.001)$ and decrease in $\mathrm{FiO}_{2}(0.984 \mathrm{PCC})$.

In 5 out 6 pigs, increasing PEEP effectively improved oxygenation of the saline injured lung while maintaining a constant $\mathrm{RR}(20 \mathrm{bpm}), V_{T}(400 \mathrm{~mL})$ and flow rate $(5 \mathrm{~L} / \mathrm{min})$ (Fig. 3E). Incremental PEEP steps from 5 to $20 \mathrm{~cm} \mathrm{H}_{2} \mathrm{O}$ led to significant increase in $\mathrm{PaO}_{2}$ from $62.3 \pm 7.4 \mathrm{~mm} \mathrm{Hg}[8.3 \pm 0.99 \mathrm{kPa}$ ] to $287.5 \pm 14.2 \mathrm{~mm} \mathrm{Hg}[38.3 \pm 1.9 \mathrm{kPa}]$ $(p<0.01)$.

\section{ABBU synchronous operation testing}

A breath-triggering software algorithm was developed during the first four pig studies, with over 1000 breaths analyzed with each experiment. After each study, the algorithm was tuned. A "true positive" is defined as the patient initiating a breath (e.g., triggeredassisted breath) and ABBU delivering an assist within 160 ms. A "true negative" (e.g., control breath) is defined as the patient not initiating a breath and ABBU delivering a breath according to the rate setting. A "false positive" is defined as ABBU delivering a breath at a time the patient did not initiate (e.g., false triggering or auto-cycling). A "false negative" (e.g., ineffective triggering) is defined as the patient initiating a breath and ABBU not delivering an assist. False positives occurred during suction and airway disconnect. To remove these false positives, we added two blanking times, when the algorithm does not look for patient assist. The first blanking time is shown in Fig. 4A 


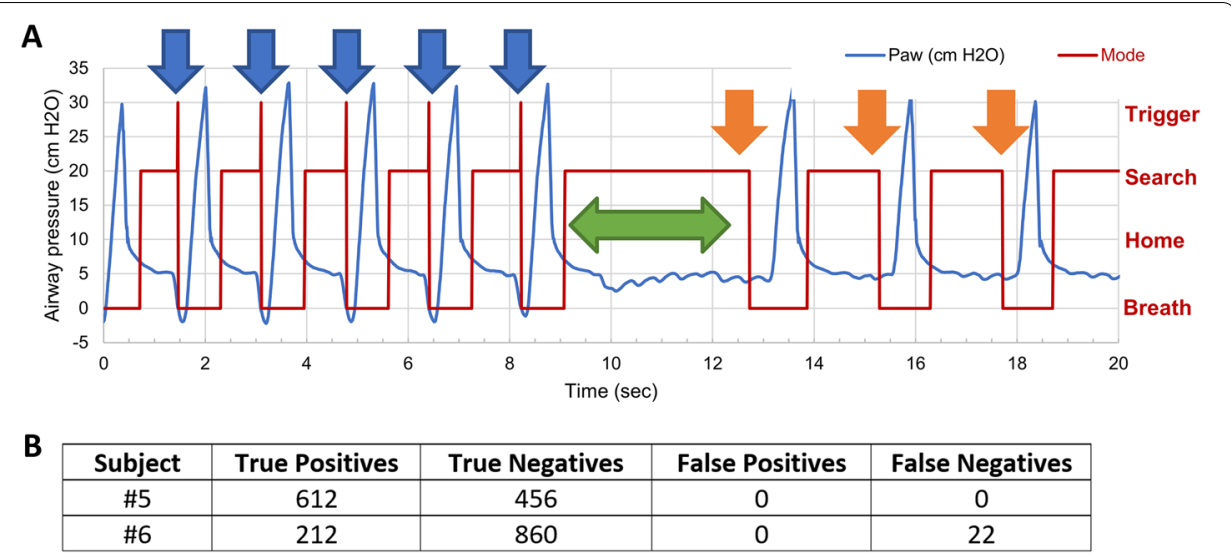

Fig. 4 ABBU breath triggering data. A Representative pressure-time scalar (blue) during one porcine experiment. The first five breaths are trigger assisted (blue arrows), followed by a two respiratory cycle pause (green arrow), followed by three control breaths (orange arrows). Mode = Breath means a mechanical breath is being is delivered, Mode $=$ Home means the motor is idle and Paw is below PEEP, Mode $=$ Search is when it calculates PEEP and is searching for a patient effort, and Mode = Trigger means a breath assist is triggered. B Summary of trigger assist algorithm $(n=2)$. Note that Subject \#6 had 22 false negatives (ineffective triggering) attributed to inability of the algorithm to calculate the sensing threshold below PEEP during periods of rapid breathing (50-60 bpm)

as the time between mode $=$ Breath ( start of delivered breath) and mode $=$ Home (end of delivered breath when motor returns to home) eliminates the period, while the bag is being compressed and the airway pressure is changing rapidly. Mode $=$ Home is when the motor is home, the airway pressure is below PEEP. Mode $=$ Search is when the motor is home, the airway pressure is above the previous PEEP, the algorithm calculates PEEP for this breath, and it searches for a patient effort. The second blanking time between Mode $=$ Home and Mode $=$ Search eliminates the false positives that would occur on suction and airway disconnect. Mode $=$ Trigger in Fig. 4A signifies the algorithm triggered a synchronous breath, because the airway dropped below the PEEP for this breath. In Fig. 4A, an asynchronous breath occurs when the algorithm cycles through modes Breath-Home-Search (orange arrows), and a synchronous breath cycles through modes Breath-Home-Search-Trigger (blue arrows). The two blanking periods also eliminated run-away, where ABBU delivered breaths above $60 \mathrm{bpm}$. However, the blanking periods causes false negatives if the patient attempts to breathe faster than $60 \mathrm{bpm}$. During the first four pig studies, false negatives occurred when the patient attempted to breathe at a rate close to the asynchronous rate set on ABBU. To eliminate these false triggers, the algorithm was modified to include a two respiratory cycle pause after a triggered breath before delivering a control breath (see the time from 9 to $13 \mathrm{~s}$ in Fig. 4A). A rapid increase in patient PEEP valve of more than $5 \mathrm{~cm} \mathrm{H} 20$ per breath causes false positives. Similarly, a rapid decrease in patient PEEP valve causes false negatives. These observations led to the recommendation to adjust the patient PEEP valve slowly, so the algorithm operates properly during the change.

The final version of the ABBU triggering algorithm (e.g., assist-control mode) was tested in 2 pigs (Fig. 4). The sensing threshold was set at $-5 \mathrm{~cm} \mathrm{H}_{2} \mathrm{O}$, and data was collected as the animal went from light anesthesia (spontaneous breathing) to deep anesthesia (paralysis). Tidal volume was adjusted from 200 to $800 \mathrm{~mL}$. PEEP valve was set 
at $5 \mathrm{~cm} \mathrm{H}_{2} \mathrm{O}$. The algorithm effectively calculated PEEP for pressure threshold sensing unless there was applied suction, circuit leaks, or rapid respiratory rates exceeding 50 bpm (Fig. 4, Panel B, Subject \#6).

\section{Discussion}

The shortage of mechanical ventilators due to the COVID-19 pandemic has led to attempts to repurpose hand-operated AMBU bags into automated bag-compression devices $[6-8,11-16]$. In 2020, our group developed and tested the Automated Bag Breathing Unit (ABBU), to assist with the shortage of conventional ventilators [1, 2]. ABBU uses widely available resuscitation bags and circuit components and can be quickly mass-produced to potentially mitigate conventional ventilator shortages. An ABBU training manual and instructional video were tested by respiratory therapy students at the University of Texas Health Sciences Center at San Antonio. A post training survey indicated that students could quickly perform circuit and basic operation set up.

ABBU is not a full-featured ICU ventilator, but a device that provides automated compression of a bag valve resuscitator. The FDA classifies these devices as "emergency resuscitators" and they typically provide controlled ventilation with a fixed oxygen flow rate, adjustable $R R$ and $V_{T}$, manual PEEP valve, and basic alarms, such as high airway pressure or power failure $[19,20]$.

To our knowledge, ABBU is the only resuscitator providing a software-based pressuresensing algorithm with adjustable triggering thresholds. This is an important feature of ventilation in patients with acute respiratory failure or when weaning patients from ventilation [21]. Despite a growing number of approved FDA Emergency Use Authorization (EUA) resuscitators, few have published specifications or pre-clinical testing results, and none have reported clinical trials in patients [22-26]. Here we report ABBU is capable of providing physiological gas exchange in a short-term $(6-8 \mathrm{~h})$ adult-size porcine model of normal and saline lavage lung injury. A saline lavage injury model was chosen for simplicity and reproducibility. Saline lavage causes surfactant washout with readily recruitable lung and rapid recovery but does not reflect the severity or heterogeneity of clinical acute respiratory distress syndrome $[17,26]$. As expected, $\mathrm{PaO}_{2}$ increased with incremental PEEP and $\mathrm{PaCO}_{2}$ decreased with incremental minute ventilation by adjusting $\mathrm{V}_{\mathrm{T}}$ or $\mathrm{RR}$.

It is important to understand that automated resuscitators, including ABBU, have significant limitations compared to fully functional ICU ventilators [9, 20, 27, 28]. Due to the use of a fixed low flow oxygen source, delivered $\mathrm{FiO}_{2}$ decreases with increases in $\mathrm{V}_{\mathrm{T}}$ or RR and may be a significant factor contributing to oxygen desaturation in patients. ABBU has no capacity for automated flow augmentation or leak compensation, such that PEEP decays during the exhalation phase. PEEP decay may be clinically significant in patients with long exhalation times, bronchopleural fistulas, or endotracheal cuffleaks, resulting in loss of lung recruitment.

Additional limitations of ABBU and similar emergency resuscitators include a lack of measuring actual $\mathrm{V}_{\mathrm{T}}$ delivery (e.g., set bag $\mathrm{V}_{\mathrm{T}}$ plus spontaneous breath $\mathrm{V}_{\mathrm{T}}$ ) which may be significantly greater than the clinician set $V_{T}$ (or less in the setting of air leaks). There is no automated inspiratory or expiratory pause feature to assess inspiratory plateau pressure or auto PEEP, respectively. In contrast to ICU ventilators, there are no pressure, 
volume, or flow graphics to assess respiratory mechanics or patient-ventilator synchrony. Patient work of breathing and ABBU-patient synchrony assessment could not be readily reproduced in this anesthetized animal model and should be evaluated in clinical trials.

The ABBU design currently does not have an integrated battery backup for use as a transport device. However, in case of electrical or motor failure, the AMBU bag may be removed from the enclosure and used manually. This feature is an advantage over resuscitation devices that rely on a continuous source of compressed air. Durability of the ABBU device may be limited by the lifespan of the electric motor and AMBU bag (approximately 30 and 7 days of continuous operation, respectively).

ABBU's limitations are inherent to the simplicity and low-cost design goal of achieving rapid mass production in a ventilator shortage scenario. These deficiencies are potentially addressable by close patient monitoring to include use of pulse oximetry, end-tidal $\mathrm{CO}_{2}, \mathrm{FiO}_{2}$ analyzer, and a $\mathrm{V}_{\mathrm{T}}$ respirometer. At the time of this writing, an application for FDA Emergency Use Authorization has been submitted and is pending review.

\section{Conclusions}

The ABBU emergency resuscitator supports short term oxygenation and ventilation in an animal model across a range of parameter settings that may potentially provide a lowcost solution to adult ventilator shortages. Clinical trials of ABBU (and similar emergency resuscitation bag devices) are necessary to establish safety and efficacy before use in patients with diverse etiologies of respiratory failure.

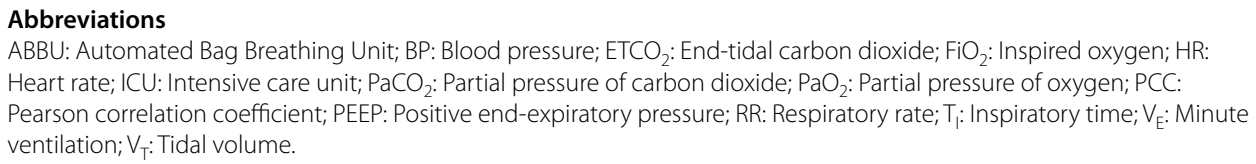

Acknowledgements

Not applicable

\section{Authors' contributions}

Innovation team: AZ, VNT, NV, MDF, RW, TEM, and SD Project team: ABG, NK, AGC, SFJ, JWV, TBP, ABM, RKL, AZ, MDF, TEM and SD. Regulatory team: VNT and NV. Design and engineering: NK, SFJ, JWV, TBF, ABM. AZ, TEM, and SD. Bench testing: NK, SFJ, JWV, ABM, and SD. Usability and pre-clinical studies: ABG, AGC, MDF, RW, and SD. Writing and revision of the manuscript: ABG, SD, NK, JWV, MDF, and TEM Study supervision: TEM, MDF, and SD. All authors read and approved the final manuscript.

\section{Funding}

The study was supported by UTHSCSA Clinical and Translational Science Award, Texas Innovation Center at the University of Texas at Austin.

Availability of data and materials

The data sets generated and analyzed during the current study are available from the corresponding author on reasonable request.

\section{Declarations}

Ethics approval and consent to participate

Animal study was approved by the Institutional Animal Care and Use Committee at the University of Texas Health Science Center at San Antonio.

\section{Consent for publication}

Not applicable.

Competing interests

The authors declare that they have no competing interest. 


\begin{abstract}
Author details
${ }^{1}$ Department of Medicine, UT Health San Antonio, 7703 Floyd Curl Drive, DTL 5.532U, San Antonio, TX 78229, USA. ${ }^{2}$ Beckman Laser Institute, The University of California Irvine, Irvine, CA, USA. ${ }^{3}$ UT Austin Cockrell School of Engineering, The University of Texas, Austin, TX, USA. ${ }^{4}$ ThermoTek, Inc, Flower Mound, TX, USA. ${ }^{5}$ School of Health Professions, UT Health San Antonio, San Antonio, TX, USA. ${ }^{6}$ Dell Medical School, UT Austin, Austin, TX, USA.
\end{abstract}

Received: 1 May 2021 Accepted: 24 September 2021

Published online: 18 October 2021

\title{
References
}

1. Azar II AM. Determination that a public health emergency exists. https://www.phe.gov/emergency/news/healthacti ons/phe/Pages/2019-nCoV.aspx. Accessed 15 Jan 2021.

2. Ranney ML, Griffeth V, Jha AK (2020) Critical supply shortages - the need for ventilators and personal protective equipment during the COVID-19 pandemic. N Engl J Med 382:e41

3. Rosenbaum L (2020) Facing COVID-19 in Italy_ethics, logistics, and therapeutics on the epidemic's front line. N Engl J Med 382:1873-1875

4. Meng L, Qiu H, Wan L et al (2020) Intubation and ventilation amid the COVID-19 outbreak. Anesthesiology. https://doi. org/10.1097/ALN.0000000000003296

5. Tirupakuzhi Vijayaraghavan BK, Nainan Myatra S, Mathew M et al (2020) Challenges in the delivery of critical care in India during the COVID-19 pandemic. J Intensive Care Soc. https://doi.org/10.1177/1751143720952590

6. Bainbridge R. The global push to increase ventilator production. https:/www.tij.com/latest/news/global-push-increaseventilator-production. Accessed 17 Jan 2021.

7. Vasich T. UCI team initiates effort to build 'bridge' ventilators. UCI News. 2020. https://news.uci.edu/2020/04/01/uciteam-initiates-effort-to-build-bridge-ventilators. Accessed 15 Jan 2021.

8. Nacharaju D, Menzel W, Fontaine E et al (2020) Three-dimensional printed ventilators: a rapid solution to coronavirus disease 2019-induced supply-chain shortages. Crit Care Explor. https://doi.org/10.1097/CCE.0000000000000226

9. Pearce JM (2020) A review of open-source ventilators for COVID-19 and future pandemics [version 2; peer review: 3 approved]. F1000Res 9:218

10. COVID-19 Map [Internet]. Johns Hopkins Coronavirus Resource Center. https://coronavirus.jhu.edu/map.html. Accessed 25 Mar 2021.

11. Kleinpell R, Ferraro D, Maves RC et al (2020) Coronavirus disease 2019 pandemic measures: reports from a national survey of 9,120 ICU clinicians. Critical Care Med 48(10):e846-e855

12. Madani K. How a small team of researchers, designers, and engineers at fitbit created an emergency ventilator to help save Lives. https://blog.fitbit.com/fitbit-flow. Accessed 17 Jan 2021.

13. Lo J. Virgin orbit ventilators. https://virginorbit.com/ventilators. Accessed 17 Jan 2021.

14. Austin P51. https://www.p51 ventilators.com. Accessed 21 Jan 2021.

15. Bahmer M. FDA approves enhanced version of Rice ventilator. Today's medical developments. https:/wwww.todaysmedi caldevelopments.com/article/fda-approves-rice-ventilator-apollo-abvm-emergency-use. Accessed 13 Jan 2021.

16. LifeMech: Machines saving lives. https://lifemech.org. Accessed 2 Feb 2021.

17. Russ M, Kronfeldt S, Boemke W et al (2016) Lavage-induced surfactant depletion in pig as a model of the acute respiratory distress syndrome (ARDS). J of Visualized Experiments 115:53610

18. Griffiths MJD, McAuley DF, Perkins GD et al (2019) Guidelines on the management of acute respiratory distress syndrome. BMJ Open Respir Res 6(1):e000420

19. Brown AFT, Lipman J (2008) Chapter 28 prehospital care. In: Papadakos PJ, Lachmann B (eds) Mechanical ventilation. Elsevier, Amsterdam, pp 307-319

20. Branson R, Dichter JR, Feldman H et al (2021) The US strategic national stockpile ventilators in coronavirus disease 2019: a comparison of functionality and analysis regarding the emergency purchase of 200,000. Devices Chest 159(2):634-652

21. Mora Carpio AL, Mora JI (2021) Ventilator management. In: StatPearls [Internet]. Treasure Island (FL): StatPearls Publishing; Available from: https://www.ncbi.nlm.nih.gov/books/NBK448186/

22. Dhanani J, Pang G, Pincus J et al (2020) Increasing ventilator surge capacity in COVID-19 pandemic: design, manufacture and in vitro-in vivo testing in anaesthetized healthy pig of a rapid prototype mechanical ventilator. BMC Res Notes 13:42

23. Fang Z, Li Al, Wang H et al (2020) AmbuBox: a fast deployable low-cost ventilator for COVID-19 Emergent Care. SLAS Technol 25(6):573-584

24. Petsiuk A, Tanikella NG, Dertinger S et al (2020) Partially reprapable automated open source bag valve mask-based ventilator. HardwareX 8:e00131

25. SVASTA, PRANA and VaU: Three Novel Ventilators from Space Community (2020) Trans Indian Natl Acad Eng 5(2):355-364.

26. Matute-Bello G, Frevert CW, Martin TR (2008) Animal models of acute lung injury. Am J Physiol Lung Cell Mol Physiol 295:L379-L399

27. Badnjevic A, Gurbeta L, Jimenez ER et al (2017) Testing of mechanical ventilators and infant incubators in healthcare institutions. Technol Heal Care 25(2):237-250

28. Kakkar K, Gupta B (2020) Is the use of automated artificial manual breathing unit resuscitators justified during a pandemic mechanical ventilator crisis? Acute Criti Care 35(3):220-222

\section{Publisher's Note}

Springer Nature remains neutral with regard to jurisdictional claims in published maps and institutional affiliations. 